\title{
Pengembangan Kerukunan Masyarakat Multikultural Melalui Pendekatan Agama
}

\author{
Developing Multicultural Society via Religious Approach
}

\author{
HARJONI DESKY* \& SYAMSUL RIJAL ${ }^{1}$
}

\begin{abstract}
Studies on religious tolerance are very important to do, especially in the context of the pluralistic Indonesian nation. In the framework of multiculturalism, religion must transcend the boundaries of language, ethnicity and also particular cultures. Religion is no longer itself separate from worldly projects and other dimensions. Religion that has entered a multicultural society will experience an acculturation process so that religion can have many versions, especially in the aspect of implementation. Starting from the perspective of understanding to the importance of religion in accordance with the culture of each region or place. It is from this multicultural society that differences in expression are born in carrying out religious orders. The role becomes very important when religion has been embraced by human social groups, which are associated with meeting the complex needs of human life in society. In a sociological perspective, religion is seen as a belief system that is manifested in certain social behaviors. Religion deals with human experience, both as individuals and groups. Therefore, the behavior played by individuals or groups will be related to the belief system of their religious teachings. Individual and social behavior is driven by internal strength, which is based on internalized religious values and has become one of the important pillars in shaping a harmonious, just and prosperous society.
\end{abstract}

Keywords: harmony, religion, multiculturalism, tolerance

Kajian toleransi beragama tetap penting dilakukan, terutamanya dalam konteks bangsa Indonesia yang majmuk. Kemajmukan dalam agama, bahasa, etnik, suku, dan adat istiadat memerlukan sebuah sofistifikasi pengurusan konflik, sehingga konflik dengan ketegangan secara berkesinambungan dapat dikelola dengam baik (Gunawan \& Rante 2001). Elemen-elemen kemajmukan tersebut, baik sendirian mahupun bersama-sama, boleh mengancam integrasi bangsa. Disintegrasi sosial, konflik dan ketegangan di masyarakat Indonesia dilihat dari sejarah kemunculannya sering dipicu oleh masalah-masalah yang terkait dengan agama dan kesukuan (seperti rusuhan yang terjadi di beberapa daerah), atau agama dan etnik atau kesukuan sering difahami "mengilhami" tindakan kekerasan seperti peledakan bom di tempat-tempat ibadah dan tempat-tempat awam (William \& Geertz 1961).

Perlu diakui bahawa elemen agama menyumbang kepada kehidupan manusia. Keyakinan terhadap supernatural adalah awal dari pemaknaan dunia realiti. Sehingga manifestasi nilai-nilai agama yang dianut akan menggejala pada aktiviti dan perilaku kehidupan sosial keagamaan sebuah komuniti (Rijal 2019). Namun, di sisi lain pemahaman yang sempit atas elemen agama

${ }^{1}$ Harjoni Desky*, Ph. D. (Corresponding author), Lecturer at the Faculty of Economics and Islamic Business, State Institute of Islamic University (IAIN) Lhokseumawe, Jl. MedanBanda Aceh Km 275 No.1 Buket Rata Alue Awe, Kecamatan Muara Dua Lhokseumawe 24352, INDONESIA. Email: harjonidesky@iainlhokseumawe.ac.id; Syamsul Rijal, Ph. D. Prof. at the State Islamic University (UIN) Ar-Raniry, Jl. Syeikh Abdul Rauf Darussalam, Banda Aceh, 23111 INDONESIA. Emaill: literasi.syamsulrijal@ar-raniry.ac.id 
memunculkan disintegrasi sosial dibandingkan elemen lain (Hermawati, Paskarina, \& Runiawati 2017). Terlepas dari kompleksiti lain yang menyumbang pada aksi-aksi kerusuhan sosial dan tindakan kekerasan, faktor agama dianggap paling penting untuk diperhatikan, kerana agama sering disandarkan dalam bentuk lain yang mampu menjadi dorongan atau selalu mengandungi imajinasi yang membuat pelbagai nilai jadi mutlak; agama dengan itu juga memprojekkan apa yang disebut oleh Karren Amstrong sebagai 'perang kosmis'(Rosidah 2016).

Perang kosmis dapat difahami sebagai "perjuangan" yang dilakukan antara kekuatan Baik dan Jahat. Sementara itu agama sering dianggap membenarkan kekerasan dan kekerasan memperkukuhkan agama, yang dalam kehidupan publik memberikan ke arah peraturan moral. Kaum radikal agama (perspektif kaum radikalis) yang memiliki pemahaman seperti itu selalu menempatkan dirinya sebagai paling benar dan memiliki legitimasi keTuhanan yang sah untuk memusnahkan 'yang lain' (Isnaini 2017). Agama sering difahami hanya sebagai nalar teologi yang mengagungkan Tuhan dan ritual-ritual, tetapi kurang memperhatikan masalah-masalah kemanusiaan (Arkoun 2003).

Pemahaman tersebut menurut Hassan Hanafi disebut teologi yang berorientasikan pada watak antroposentrisme atau menurut Arkoun disebut sebagai nalar kritis, yaitu sebuah watak yang mengharuskan agama peduli pada masalah pembangunan tata moral masyarakat dan lingkungan (Azra 2016). Tafsir-tafsir keagamaan seperti ini tentu bukan masa depan peradaban manusia moden. Modenisasi sekarang menjadi sebahagian daripada kehidupan manusia cenderung memiliki landasan orientasi materialistik sebagai nilai normatif tata masyarakat moden (Umiarso \& Rijal 2020).

Orientasi materialistik dalam kehidupan moden selalu berhadapan dengan nilai-nilai keagamaan yang dianut seseorang. Di sisi lain, agama walau masih dijadikan ideologi, yang sering disebut sebagai ideologisasi agama, kewujudannya masih mengancam. Seperti api dalam sekam atau bom waktu, ia akan menguat dan kukuh apabila faktor-faktor pemicunya seperti ketidakadilan dan kesenjangan kebudayaan. Padahal bila dilihat dari kandungan nilai-nilai yang dimiliki setiap agama, tidak ada agama yang menganjurkan kekerasan dan menganjurkan kebencian (Ummah 2012). Membangun kehidupan yang penuh toleransi beragama harus diletakkan dalam kerangka pembangunan teologi yang inklusif dalam peradaban multikutural.

Peradaban multikultural telah menjadi ciri paling utama dalam kehidupan manusia dewasa ini (Osman 2008). Perbezaan tidak lagi dipandang sebagai sesuatu keanehan. Dalam konteks idea multikutural, perbezaan-perbezaan (agama, budaya, etnis, bahasa adat istiadat) dianggap sebagai suatu mozaik kultural yang tidak saling menegaskan tetapi justru saling menumpang dengan membentuk jaring-jaring kerjasama dengan identiti masing-masing. Masyarakat yang multikultural dalam menciptakan kehidupan yang rukun, sangat tergantung dengan gaya kepemimpinan negara atau daerah yang diterapkan, dan gaya yang ideal adalah gaya kepemimpinan yang partisipatif, konsultatif, dan transformasional (Abror, Suraji, Moeheriono, Al Walid, \& Harjoni 2020).

Konsep ini yang kemudian disebut sebagai fahaman multikultural atau multikulturalisme. Dalam kerangka multikulturalisme, agama harus melampaui batas-batas bahasa, etnis dan juga budaya tertentu. Agama tidak lagi menjadi diri sendiri yang terpisah daripada kegiatan keduniaan dan dimensi lain. Dalam pengertian Abdul Aziz Sachedina ini disebut teologi multikultural (Omar 2004). Sebuah teologi yang menggambarkan perhatian dan kepedulian terhadap penduduk dunia, mempengarui kehidupan mereka melampaui batas-batas komuniti dan budaya. Agama juga berusaha membebaskan manusia daripada belenggu kemiskinan, penindasan, dan ketidakadilan akibat daripada hubungan dominasi-subordinasi, menindastertindas, Barat-Timur, superior-inferior sama ada dalam hubungan antara agama, etnik ataupun budaya (Baidi 2010).

Teologi seperti ini memperluaskan peranan bukan sahaja untuk kepentingan kelompok etnik, bangsa, dan kebudayan tertentu, tetapi juga bertanggungjawab atas keseluruhan kesejahteraan dunia. Pada sisi lain, pengalaman umat manusia dalam sejarah pertumbuhan dan perkembangan budaya dan peradaban menunjukkan bahwa semakin banyak terjadi pertukaran 
silang, semakin kuat dan kaya budaya dan peradaban yang terbentuk. Sebalikinya, semakin kurang pertukaran silang itu akibat isolasi sosial, semakin miskin pula budaya dan peradabannya.

Oleh itu, dalam masyarakat multikultural, kesatuan tidak difahami sebagai monolitisme yang statik, tetapi sebagai kesatuan dalam keanekaan yang dinamis dan produktif. Konsep ini dalam konteks bangsa Indonesia disebut Bhinneka Tunggal Ika. Dalam konteks umat Islam Indonesia, idea teologi multikutural bukan sesuatu yang sukar untuk dikembangkan. Islam Indonesia adalah Islam yang dikenal sangat moderat. Moderasi ini tumbuh secara organik dari akar-akar sejarah. Islamisasi yang terjadi bermula daripada cara-cara yang sangat multikultural yang ditandai oleh pengakuan oleh nilai-nilai lokal berdampingan dengan nilai-nilai lain (Rusydi \& Zolehah 2018).

\section{Definisi Multikultural}

Kata multikultural adalah gabungan daripada dua perkataan iaitu 'multi' dan 'kultural'. Secara umum kata 'multi' diertikan sebagai suatu yang jamak. Sedangkan kata 'kultural' berasal dari bahasa Inggeris dari kata culture yang padanan kata dalam bahasa Indonesia ialah budaya. Budaya berasal dari bahasa Sansekerta, merupakan gabungan kata dari 'budhi' dan 'daya' yang bererti budi atau akal. Budaya menurut P.J. Zoetmulder sebagaimana yang dikutip oleh Koentjaraningrat (2010) adalah segala hasil dari segala cipta usaha dan rasa.

Multikulturalime meliputi sebuah pemahaman, penghargaan dan penilaian atas budaya seseorang, serta sebuah penghormatan dan keingintahuan tentang budaya etnik orang lain. Ia meliputi sebuah penilaian terhadap budaya-budaya orang lain, bukan dalam erti menyetujui seluruh aspek dari budaya-budaya tersebut, melainkan cuba melihat bagaimana sebuah budaya yang asli dapat mengekspresikan nilai bagi anggota-anggotanya sendiri (Budimansyah 2010).

Pemaknaan multikulturalisme ini juga dipaparkan oleh Bikhu Parekh sebagaimana dikemukakan oleh Shofa (2016) bahawa multikulturalisme adalah cara pandang kebudayaan yang diwujudkan secara konkrit dalam kehidupan yang nyata. Terminologi multikulturalisme menurut Stavenhagen (2008) mengandungi dua pengertian: pertama, ia merupakan realiti sosial dalam masyarakat majmuk dan kedua, multikulturalisme bererti keyakinan atau kebijakan yang menghargai pluralisme budaya sebagai khazanah kebudayaan yang diakui dan dihormati keberadaannya. Sejajar dengan terminologi di atas, Suparlan (2014) mengemukakan bahawa kata kunci dalam multikulturalisme ini adalah "perbezaan" dan "penghargaan", dua kata yang selama ini sering dikonfrontasikan.

Multikulturalisme adalah landasan budaya yang terkait dengan pencapaian civility (keadaban), yang amat esensial bagi terwujudnya demokrasi yang berkeadaban, dan keadaban yang demokratik. Negara-negara yang menganut sistem demokrasi, pada umumnya mempunyai kesedaran yang tinggi tentang pentingnnya multkulturalisme untuk membangun torelansi, asimilasi, dan persamaan hak di antara warganegara. Semua ini merupakan faktor utama dalam konsolidasi dan pendalaman demokrasi sehingga negara-bangsa tersebut mampu bertahan dan berterusan. Yang tidak kurang pentingnya dalam membangun demokrasi multikultural adalah pengakuan atas kekurangan dan kelemahan yang pernah terjadi dalam upaya menguatkan nation-building (Sutherland 2005).

Multikulturalisme merupakan pengakuan bahawa beberapa budaya berbeza dapat wujud dalam lingkungan yang sama dan menguntungkan satu sama lain. Atau pengakuan dan promosi terhadap pluralisme budaya. Ada yang menyebutkan bahawa multikulturalisme sebagai menghargai dan berusaha melindungi keragaman budaya (Junaidi 2018). Suryadinata (2014) menyebutkan bahwa multikulturalisme menghargai dan berusaha melindungi keragaman kultural. Multikulturalisme bukanlah sebuah doktrin politik pragmatik, ia adalah sebuah cara pandang (paradigma) kehidupan manusia. Kata multikulturalisme pertama kali digunakan di Kanada tahun 1960-an. Perdana Menteri Kanada, Pierre Trudeau, menggunakannya untuk melawan konsep biculturalism (Jamrozik \& Nocella 2011). Di masa sebelumnya, Kanada dikenal hanya terdiri atas dua etnik yang saling bersaing: Inggeris dan Perancis. Semenjak Trudeau, dinyatakan bahwa Kanada multikultural kerana terdiri atas etnik dan ras berbeza seperti 
Inggeris, Perancis, Indiaen, serta kaum imigran dari manca negara seperti Cina, India, Jerman, Arab dan sebagainya (Kymlicka 2011).

Studi multikulturalisme kemudian disistematikkan dan dipopularkan oleh Will Kymlicka melalui dua karyanya Liberalism, Community and Culture (1989) dan Multicultural Citizenship (1995). Bagi Kymlicka (2015), pemberian ruang bagi kalangan minoriti suatu negara tidak dapat dicapai hanya melalui jaminan hak-hak individu dalam undang-undang. Minoriti yang dimaksudkan Kymlicka adalah minoriti budaya, yang secara praktik sosial sehari-hari harus diperhatikan keunikan identitinya. Gerakan multikultural tersebut kemudian muncul di Australia, Amerika Syarikat, Britain, Jerman dan lain-lainnya.

\section{Peranan Agama dalam Masyarakat Multikultural}

Agama yang memasuki dalam masyarakat multikultural akan mengalami proses akulturasi sehingga ia memiliki banyak versi khususnya dalam aspek implementasi. Mulai dari segi pemahaman sampai pada erti penting agama sesuai dengan budaya daerah masing-masing. Dari masyarakat multikultural inilah lahir perbezaan ekspresi dalam melaksanakan perintah agama. Peranan agama menjadi sangat penting ketika ia telah dianuti oleh kelompok-kelompok sosial manusia, yang terkait dengan pemenuhan keperluan hidup yang kompleks dalam masyarakat.

Pada perkembangan demikian itulah agama menjadi berkaitan langsung dengan kebudayaan dalam masyarakat sehingga agama dan masyarakat serta kebudayaan mempunyai hubungan timbal balik yang saling mempengaruhi (Suparlan 2001). Hubungan agama dan kebudayaan ini sering menjadi dasar bagi lahirnya keputusan dan kebijakan pemerintah, salah satu contoh, terjadinya konversi bank daerah (BPD) di Aceh keapada Bank Aceh Syariah (Desky, Harjoni \& Iskandar 2020). Aspek falsafah, sosiologi, hukum dan ekonomi telah melahirkan perkara baru dalam dunia kewangan syariah.

Di sisi lain, agama dan masyarakat serta kebudayaan dalam perspektif sosiologi, agama dipandang sebagai sistem kepercayaan yang diwujudkan dalam perilaku sosial tertentu. Agama berkaitan dengan pengalaman manusia, baik sebagai individu ataupun kelompok. Oleh itu, perilaku yang dimainkan oleh individu ataupun kelompok itu akan terkait dengan sistem keyakinan daripada ajaran agama yang dianutnya. Perilaku individu dan sosial digerakkan oleh kekuatan dari dalam, yang didasarkan pada nilai-nilai ajaran agama yang telah menginternalisasi. Agama dapat dipandang sebagai kepercayaan dan perilaku yang diusahakan oleh suatu masyarakat untuk menangani masalah yang tidak dapat dipecahkan oleh teknologi dan teknik organisasi yang tidak diketahuinya (Jamil 2013).

Keadaan masyarakat yang multikultural juga pernah terjadi dalam sejarah Islam. Pada masa kejayaan Islam di Baghdad dan Cordoba, masyarakat di kota-kota tersebut adalah sangat plural. Dengan segala kemampuannya untuk menyesuaikan keadaan kondisi sosial yang multikultural ini, Islam akhirnya tetap wujud dan berjaya. Sejarah mencatat bahawa sikap toleransi dan inklusif merupakan kunci dalam masyarakat multikultural. Sikap toleransi telah ditunjukkan oleh para pemerintah Muslim ketika mereka menakluk beberapa wilayah seperti Mesir, Syiria dan Persia.

Ilmu pengetahun yang sudah berkembang dengan pesat di wilayah-wilayah itu didukung oleh Islam untuk terus berkembang. Tidak hanya itu, komuniti agama lain seperti Kristian, Yahudi dan bahkan Zoroaster juga dibolehkan menjalankan agama masing-masing dengan bebas. Sikap inklusif atau terbuka juga dilihat pada para sasterawan dan failasuf Muslim pada masa keemasan Islam. Selain menggunakan al-Quran dan hadis sebagai sumber yang paling berautoriti, mereka juga menggunakan sumber-sumber dari kebudayaan lain (Hilmy 2015).

Fakta sejarah tersebut, kembali menunjukkan agama tetap berperanan kerana kemampuannya menyentuh sisi personal sekaligus sisi sosial seseorang atau sebuah masyarakat. Isu-isu seperti keragaman budaya, preservasi lingkungan, kesetaraan ekonomi, dan resolusi konflik, diakomodasi dalam ajaran-ajaran agama (Islam) (IT., Rijal, \& Hudi Prasojo 2019). Pada waktu tertentu, respons agama terhadap kecenderungan multikulturalisme pelbagai. Ini disebabkan, agama kerap difahami sebagai wilayah sakral, metazisik, abadi, samawi dan mutlak. 
Bahkan, pada saat agama terlibat dengan urusan 'duniawi' sekalipun, hal ini tetap demi penunaian kewajiban untuk kepentingan 'samawi.' Berbagai agama, tentu saja, berbeza dalam perkara cara dan berbagai aspeknya, namun agama-agama tersebut hampir seluruhnya memiliki sifat-sifat tersebut (Raharjo 1999). Kerana sakral dan mutlak, adalah sukar bagi agama-agama untuk mentoleransi atau hidup berdampingan dengan tradisi kultural yang dianggap bersifat duniawi dan relatif. Oleh itu, persentuhan agama dan budaya lebih banyak memunculkan persoalan daripada manfaat. Apalagi, misalnya dalam konteks Islam, kemudian dikembangkan konsep bid'ah yang sama sekali tidak memberikan ruang akomodasi bagi penyerapan budaya non-agama (Mawardi 2015).

Sebenarnya, cita-cita agung multikulturalisme tidak bertentangan dengan agama; namun demikian asas teorinya tetap bermasalah. Nilai-nilai multikulturalisme dianggap extra-religious yang ditolak oleh para ahli teologi Muslim sehingga sukar untuk meneroka tema tersebut. Memang kebelakangan ini muncul usaha yang dilakukan sejumlah pemikir Arab, seperti Mohammed Abed al-Jabiri, Hassan Hanafi, Nasr Hamid Abu-Zaid dan lain-lain, untuk merekonsiliasi antara tradisi dan agama. Namun, gagasan-gagasan mereka mendapat penenetangan keras dari ulama-ulama konservatif.

Sedangkan Tuhan dalam kitab-Nya menyeru tentang multikulturalisme (al Quran, alHujurat : 13) "Wahai manusia, Kami telah menciptakan kamu dari diri yang satu, laki-laki dan perempuan dan Kami telah menjadikanmu berbangsa-bangsa dan bersuku-suku, agar kamu dapat saling mengenal. Sungguh, yang paling mulia di antaramu di mata Allah adalah yang paling bertakwa di antara kamu. Sungguh, Allah adalah Maha Mengetahui" (Kementerian Agama 2020). Perlu dicatat bahawa ayat ini tidak hanya ditujukan bagi Muslim atau golongan secara eksklusif, tetapi ia diawali dengan seruan yang inklusif, "wahai manusia." Inilah seruan yang mencakup semuanya.

Seruan ini mengingatkan manusia bahawa mereka adalah satu keluarga besar, dengan moyang yang sama, meskipun mereka hidup dalam keluarga yang berbeza. Ini adalah peringatan bahawa 'perbezaan dalam kesatuan dan kesatuan dalam perbezaan' adalah mungkin. Manusia layaknya seikat kembang, masing-masing bunga memancarkan keindahannya, sementara kombinasi dari semua bunga yang berwarna-warni itu akan memancarkan pemandangan yang lebih indah. Pernyataan dalam al-Quran yang meyakinkan tentang luasnya persaudaraan manusia ini adalah dasar yang sangat kukuh bagi kedamaian untuk semua (Badawi 1991).

Upaya membangun hubungan sinergi antara multikulturalisme dan agama memerlukan dua perkara. Pertama, penafsiran semula ke atas doktrin-doktrin keagamaan ortodoks yang sementara ini dijadikan alasan untuk bersikap eksklusif dan opresif. Penafsiran semula itu harus dilakukan sedemikian rupa sehingga agama bukan saja bersikap reseptif terhadap kearifan tradisi lokal, tetapi juga memandu di masa depan untuk melahirkan demokrasi dalam masyarakat beragama. Kedua, mendialogkan agama dengan gagasan-gagasan moden. Ketika ini, umat beragama memasuki suatu fasa sejarah baru di mana mereka harus mampu beradaptasi dengan peradaban-peradaban besar yang tidak didasarkan pada agama, seperti budaya Barat moden. Kita tidak mungkin menghindari idea dan teori sekuler. Ini bererti, menyentuh istilah-istilah dengan gagasan non-religious merupakan tugas paling mencabar yang dihadapi kaum Muslim pada zaman moden ini.

Hanya dengan transformasi internal dan interaksi dengan gagasan-gagasan moden, agama akan mampu melakukan reformulasi sintesis kreatif terhadap tuntutan multikulturalisme yang telah menjadi semangat zaman. Bukankah agama mengalami kejumudan saat berhenti belajar dan berdialog dengan peradaban lain? Sekarang saatnya untuk merevitalisasi persenyawaan agama dengan berbagai realiti yang mengitarinya. Peranan agama dalam keadaan masyarakat yang majmuk adalah salah satunya sebagai penguat sosial. Sebuah teori yang dikemukakan oleh Emile Durkheim dalam bukunya The Elementary Forms of Religious Life. Dengan unsur solidariti agama memiliki fungsi sosial (Durkheim 2016).

Agama bukan ilusi, melainkan merupakan fakta sosial yang dapat diidentifikasi dan mempunyai kepentingan sosial. Agama sebenarnya tidak berisi kepercayaan terhadap roh-roh 
atau dewa, akan tetapi lebih pada pemisahan antara yang susci dan yang keji. Dalam perspektif solidariti sosial, agama berperanan menjambatani ketegangan serta menjaga kelangsungan masyarakat ketika dihadapkan pada cabaran kehidupan. Dalam hal ini, agama berperanan menyatukan anggota masyarakat melalui deskripsi simbolik suci mengenai kedudukan mereka dalam sejarah, kosmos dan tujuan mereka dalam keteraturan sesuatu.

Agama sangat baik dalam hal pembinaan masyarakat untuk menuju pada kesejahteraan dan sekaligus nurani masyarakat itu sendiri dalam membentuk kerukunan. Salah satu alasan mengapa demikian seperti dalam Jadual berikut adalah:

\section{Konsep Keagamaan dalam Membentuk Kerukunan Ummah}

\begin{tabular}{|c|l|}
\hline No & \multicolumn{1}{|c|}{ Nilai-Nilai } \\
\hline 1 & $\begin{array}{l}\text { Agama mengajarkan nilai-nilai yang benar dan baik bagi umatnya. Agama memandu } \\
\text { umatnya untuk menjadi individu yang baik dan menjauhkannya dari segala sesuatu } \\
\text { yang bertentangan dengan ajaran agamanya }\end{array}$ \\
\hline 2 & $\begin{array}{l}\text { Agama mengajarkan cara-cara untuk memperolehi tempat yang indah di akhirat nanti } \\
\text { sebagai tujuan akhir kehidupan. Cara-cara ini berintikan pada pelaksanaan ajaran } \\
\text { agama dengan bersungguh-sunguh. Orang yang melaksanakan dengan baik akan } \\
\text { memperolehi syurga, sedangkan orang yang tidak melaksanakannya akan memasuki } \\
\text { neraka. }\end{array}$ \\
\hline 3 & $\begin{array}{l}\text { Agama yang berfokus pada ajaran cinta kasih mengajak umatnya untuk mengasihi } \\
\text { sesamanya sehingga dapat saling menghargai dan saling tolong-menolong melalui } \\
\text { institusi masing-masing yang biasanya diekspresikan dalam kegiatan-kegiatan sosial } \\
\text { mahupun keagamaan }\end{array}$ \\
\hline 4 & $\begin{array}{l}\text { Secara tidak langsung agama mendorong terciptanya perdamaian di muka bumi yang } \\
\text { terdiri atas masyarakat yang majmuk melalui ajaran-ajaran tersebut. Hal ini sejalan } \\
\text { dengan seruan Allah dalam surat Al-Maidah ayat 48 dan Surat Al-Hud ayat 118 yang } \\
\text { bermaksud "Jika Allah menghendaki, Ia boleh menjadikan semua manusia sebagai satu } \\
\text { bangsa" (Kementerian Agama 2020) }\end{array}$ \\
\hline
\end{tabular}

Melalui jadual tersebut menjelaskan ada empat konsep keagamaan yang dapat dijadikan sebagai nilai-nilai dasar dalam mewujudkan kerukunan antara umat beragama. Selain itu, seruan untuk hidup bersama secara damai dan universal sebagaimana dalam dua ayat 8-9 dalam surat Al-Mumtahanah (Kementerian Agama 2020), adalah bukti autentik bahawa keragaman merupakan keniscayaan dan nas Tuhan. Sehingga sudah sepatutnya ayat-ayat tersebut menjadikan Muslim wajib bersikap toleran dan penuh damai sebagai sesama makhluk yang hidup di dunia berdasarkan kesetaraan (qist) dan kebaikan utama (birr) (Badawi \& D 2002). Namun demikian, agama secara umum juga dapat menimbulkan kesan yang negatif dalam hal bermasyarakat, terutama pada masyarakat yang majmuk, diantaranya disebabkan:

Pertama, agama memiliki dan mengajarkan hal-hal yang bersifat eksklusif dan berbeza untuk agama yang berbeza. Hal ini mengakibatkan terjadinya perbezaan pandangan terhadap masalah-masalah tertentu. Kedua, agama memiliki cita-cita berupa misi untuk menyebarkan ajarannya seluas-luasnya. Hal ini tidak dapat dihalang, namun demikian pada masyarakat yang telah beragama seolah-olah timbul pandangan yang menyatakan terjadinya perebutan umat atas agama tertentu. Ketiga, dalam internal agama itu sendiri terkadang terjadi suatu perbezaan pandangan ataupun tafsir terhadap ajarannya sehingga muncul aliran-aliran baru dalam agama tersebut. Hal ini tentu menimbulkan kebingungan bagi masyarakat yang haus akan berita kebenaran. Perbezaan cara pandang juga dapat menimbulkan kaum ekstremis pada agama tersebut yang mengkibatkan fanatisme sempit dan penguncian diri terhadap pandangan lain. Keempat, agama memiliki potensi untuk menimbulkan suatu konflik.

Kesimpulannya, multikulturalisme adalah suatu keadaan, terutama dalam konteks Indonesia. Keragaman ras, suku, bahasa dan agama merupakan ciri khas serta kelebihan dari bangsa Indonesia yang membezakannya dengan bangsa lain. Namun demikian, perbezaan yang tidak dikelola dengan baik akan menimbulkan konflik dan perselisihan. Oleh itu, harus ada formula untuk mendamaikan dan menyatukannya. Dalam masyarakat moden, multikulturalisme lebih kompleks lagi. Sebab budaya baru terus muncul akibat akses komunikasi dan informasi 
yang tidak terkawal. Saat terjadi pertemuan antara globalisasi negara-bangsa (nation-state) dan kelompok identiti, kemunculan dari kelompok-kelompok identiti ini semakin menguat. Globalisasi akan mendorong kesedaran politik dalam kelompok-kelompok ini dan membuka kesedaran yang mendorong pentingnya identiti. Globalisasi memberikan kesempatan kepada kelompok-kelompok identiti untuk menemukan akar identitinya. Pemahaman agama, sebagai salah satu perkara penting dalam membentuk masyarakat adil dan sejahtera sangat perlu untuk diberi perhatian.

\section{REFERENCES}

Abror, R. H., Suraji, Moeheriono, Al Walid, K., \& Harjoni. 2020. Philosophical concept of leadership in supply chain affecting the community perception in the East Java government of Indonesia. International Journal of Supply Chain Management. 9 (3): 1038-1045.

Arkoun, M. 2003. Rethinking Islam today. Annals of the American Academy of Political and Social Science. 588 (1): 18-39. https://doi.org/10.1177/0002716203588001003

Azra, A. 2016. Kontestasi pemikiran Islam Indonesia kontemporer. Studia Islamika. 23 (1): 175184. https://doi.org/10.15408/sdi.v23i1.2905

Badawi, J. A. 1991. The application of tawheed in the natural and social order. Humanomics. 7 (1): 5-18. https://doi.org/10.1108/eb006110

Badawi, J. A., \& D, P. 2002. Gender Equity in Islam Basic Principles, American Trust Publications: World Assembly of Muslim Youth

Baidi, B. 2010. Agama dan multikulturalisme: pengembangan kerukunan masyarakat melalui $\begin{array}{lllll}\text { pendekatan } & \text { agama. } & \text { Millah. } & 1 & \text { (Khusus): }\end{array}$ https://doi.org/10.20885/millah.ed.khus.art1

Budimansyah, D. 2010. Tantangan globalisasi terhadap pembinaan wawasan kebangsaan dan cinta tanah air di sekolah. Jurnal Penelitian Pendidikan. 1 (1): 1-13.

Desky, H., \& Iskandar, I. 2020. The Analysis of behavioral Intention of Customers on the Conversion of Bank Aceh. 1 (1): 22-30. https://doi.org/10.4108/eai.1-10-2019.2291672

Durkheim, E. 2016. The elementary forms of religious life. In Social Theory Re-Wired: New Connections to Classical and Contemporary Perspectives: Second Edition. 5 (2): 154-167. https://doi.org/10.4324/9781315775357

El-Rumi, Umiarso \& Rijal, S. 2020. Kristalisasi Nilai materialisme dalam pembentukan perilaku konsumeristik di kalangan masyarakat perkotaan Banda Aceh. Kontekstualita. (34): 60-70. https://doi.org/10.30631/kontekstualita.v34i1.166

Gunawan, K., \& Rante, Y. 2001. Manajemen Konflik atasi dampak masyarakat multikultural di Indonesia. Jurnal Mitra Ekonomi dan Manajemen Bisnis. 2 (2): 212-224.

Hermawati, R., Paskarina, C., \& Runiawati, N. 2017. Toleransi antar umat beragama di Kota Bandung. Indonesian Journal of Anthropology. 1 (2): 105-124. https://doi.org/10.24198/umbara.v1i2.10341

Hilmy, M. 2015. Radikalisme Agama dan politik demokrasi di Indonesia Pasca Orde Baru. Miqot: Jurnal Ilmu-Ilmu Keislaman. 39 (2): 407-425. https://doi.org/10.30821/miqot.v39i2.33

Isnaini, A. 2017. Kekerasan atas nama agama. Kalam. 8 (2): 213-228. https://doi.org/10.24042/klm.v8i2.221

IT., S., Rijal, S., \& Hudi Prasojo, Z. 2019. Sufism and Religious practices in modern lifestyle. Religió: Jurnal Studi Agama-Agama. 8 (1): 1-28. https://doi.org/10.15642/religio.v9i1.1231

Jamil, M. M. 2013. Revitalisasi Islam kultural. Walisongo: Jurnal Penelitian Sosial Keagamaan. 21 (2): 271-307. https://doi.org/10.21580/ws.2013.21.2.245

Jamrozik, A., \& Nocella, L. 2011. Introduction: theoretical perspectives on social problems. in The Sociology of Social Problems: pp.1-16. https://doi.org/10.1017/cbo9780511819629.002

Junaidi, J. 2018. Model Pendidikan multikultural. Al-Insyiroh: Jurnal Studi Keislaman. 2 (1): 57-72. https://doi.org/10.35309/alinsyiroh.v2i1.3332

Kementerian Agama R.I. 2006. Al-Qur'an dan Terjemahannya. Bandung: Diponegoro.

Koentjaraningrat. 2010. Manusia dan kebudayaan di Indonesia. In, Djambatan. 
https://doi.org/10.1016/s0044-8486(97)00050-1

Kymlicka, W. 2011. Multicultural citizenship within multination states. Ethnicities. 11 (3): 114129. https://doi.org/10.1177/1468796811407813

Kymlicka, W. 2015. Solidarity in diverse societies: beyond neoliberal multiculturalism and welfare chauvinism. Comparative Migration Studies. 9 (2): 91-101. https://doi.org/10.1186/s40878-015-0017-4

Mawardi. 2015. Reaktualisasi Kerukunan antar umat beragama dalam kemajemukan sosial. Substantia. 17 (1): 55-66.

Omar Farouk, B. 2004. Islam in Malaysia: Between rhetoric and reality. NIASnytt Asia Insights. No. 4 Disember: 6-7.

Osman Bakar. 2008. Book Review: Osman Bakar. (2008) Tawhid And Science: Islamic Perspectives On Religion And Science (2nd Edition). Kuala Lumpur: Arah Publications.

Raharjo, M. D. 1999. Demokrasi, agama dan masyarakat madani. Unisia. 3 (2): 21-32. https://doi.org/10.20885/unisia.vol22.iss39.art3

Rijal, S. 2019. Metode Falsafat: alternatif pemetaan realita kehidupan sosial keagamaan. Jurnal Ilmiah Islam Futura. 1 (1): 90-95. https://doi.org/10.22373/jiif.v1i1.5260

Rosidah, N. 2016. Fundamental agama. Walisongo: Jurnal Penelitian Sosial Keagamaan. 20 (1): 124. https://doi.org/10.21580/ws.20.1.182

Rusydi, I., \& Zolehah, S. 2018. Makna kerukunan antar umat beragama dalam konteks keislaman dan keindonesian. Journal for Islamic Studies. 1 (1): 170-181. https://doi.org/10.5281/zenodo.1161580

Shofa, A. M. A. 2016. Memaknai kembali multikulturalisme Indonesia dalam bingkai Pancasila.JPK $\begin{array}{llllll}\text { Jurnal Pancasila dan Kewarganegaraan. } & 1 & \text { (1): }\end{array}$ https://doi.org/10.24269/V1.N1.2016.34-40

Stavenhagen, R. 2008. Building intercultural citizenship through education: A human rights approach. European Journal of Education. 43 (2): 161-179. https://doi.org/10.1111/j.1465-3435.2008.00345.x

Suparlan, P. 2001. Kesetaraan warga dan hak budaya komuniti dalam masyarakat majemuk Indonesia. Antropologi Indonesia. 2 (1): 1-16. https://doi.org/10.1002/jmv

Suparlan, P. 2014. Menuju masyarakat Indonesia yang multikultural. Antropologi Indonesia. 1 (3): 98-105, https://doi.org/10.7454/ai.v0i69.3448

Suryadinata, L. 2014. Kebijakan negara Indonesia terhadap etnik Tionghoa: Dari asimilasi ke $\begin{array}{lllll}\text { multikulturalisme? } & \text { Antropologi } & \text { Indonesia. } & 1 & \text { (71): }\end{array}$ https://doi.org/10.7454/ai.v0i71.3464

Sutherland, C. 2005. Nation-building through discourse theory. Nations and Nationalism. 11 (2): 185-202. https://doi.org/10.1111/j.1354-5078.2005.00199.x

Ummah, S. C. 2012. Akar radikalisme Islam di Indonesia. Humanika. 12 (1): 112-124 https://doi.org/10.21831/hum.v12i1.3657

William, S. M., \& Geertz, C. 1961. The religion of Java. The American Catholic Sociological Review. 22 (1): 33-56, https://doi.org/10.2307/3708141 